В обзоре представлены литературные данные, касающиеся основных патоморфологических особенностей аутоиммунного гепатита (АИГ) и результаты световой и электронной микроскопии в виде фотографрий и описания разных вариантов морфологических изменений в печени у пациентов с АИГ. Предложены дополнения в разделы классификации АИГ, касающиеся этиологии и происхождения АИГ, приведены клинические примеры с описанием особенностей морфологии по уточненной авторами классификации.

ключевые слова: аутоиммунный гепатит, классификация, морфология.

\title{
AUTOIMMUNE HEPATITIS: MORPHOLOGICAL ASPECTS
} V. M. Tsyrkunov, N. I. Prokopchik, V. P. Andreev Grodno State Medical University, Grodno, Belarus

The review presents literature data on the main pathomorphological features of autoimmune hepatitis (AlH) and the findings of light and electron microscopy in the form of photographs and descriptions of different variants of hepatic morphological changes in patients with AlH. Updates to the sections of the AlH classification concerning the etiology and origin of $\mathrm{AlH}$ are suggested, clinical examples are given with a description of the morphology features according to the classification specified by the authors.

Key words: autoimmune hepatitis, classification, morphology.

Автор, ответственный за переписку:

Цыркунов Владимир Максимович, д-р мед. наук, профессор; Гродненский государственный медицинский университет; e-mail: tvm111@mail.ru

Для цитирования: Цыркунов, В. М. Аутоиммунный гепатит: морфологические аспекты / В. М. Цыркунов, Н. И. Прокопчик, В. П. Андреев // Гепатология и гастроэнтерология. 2021. Т. 5, № 1. С. 5-16. https://doi. org/10.25298/2616-5546-2021-5-1-5-16

\section{Введение}

В начале 1950-х годов был описан новый вид хронического гепатита у молодых женщин с прогрессирующим характером течения и обычно со смертельным исходом [1]. Дополнительными клиническими проявлениями такого гепатита было наличие артралгии, эндокринной дисфункции, кожных стрий и угревой сыпи, очень высокий уровень иммуноглобулинов в сыворотке, коррелирующий с повышением содержания плазматических клеток в печени [2]. В 1955-56 гг. после подтверждения у части таких пациентов красной волчанки был предложен термин «волчаночный гепатит», однако спустя десятилетие этот термин был заменен термином «аутоиммунный гепатит» (АИГ), который в 1990-е гг. принят Международной группой по изучению АИГ (IAIHG) [3].

В настоящее время АИГ - это сложное иммуноопосредованное заболевание печени, которое диагностируется гистологически по интерфейсному гепатиту, высоким уровням в сыворотке крови АлАТ, АсАТ, IgG и разных классов аутоантител [4].

На территории Европы частота встречаемости АИГ составляет 16-18 пациентов на 100000 человек. Заболевание встречается во всех возрастных группах, чаще болеют женщины (10-30
Corresponding author:

Tsyrkunov Vladimir, PhD, MD (Medicine), Professor; Grodno State Medical University; e-mail: tvm111@mail.ru

For citation: Tsyrkunov VM, Prokopchik NI, Andreev VP. Autoimmune hepatitis: morphological aspects. Hepatology and Gastroenterology. 2021;5(1):5-16. https://doi. org/10.25298/2616-5546-2021-5-1-5-16

лет, 50-70 лет), у детей АИГ может появиться в возрасте от 6 до 10 лет [5].

В последние годы появляется все больше свидетельств того, что ключевые патологические факторы развития болезни - генетическая предрасположенность, молекулярная мимикрия и дисбаланс между эффректорным и регуляторным иммунитетом в конкретной аутоиммунной экосистеме (рис. 1).

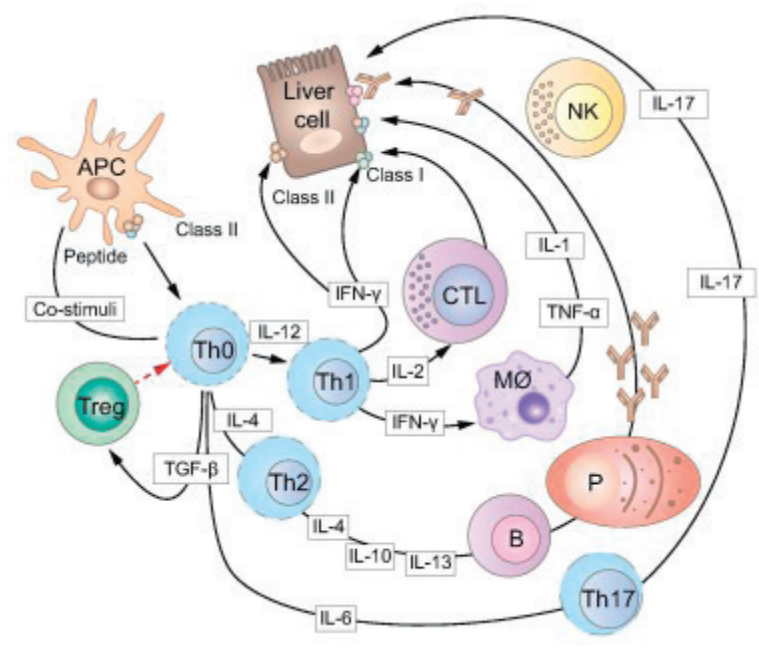

Рисунок 1. - Молекулярный патогенез АИГ [6, 7] Figure 1. - Molecular pathogenesis of AlH [6, 7] 
Общим для существующих теорий развития АИГ является генетически обусловленная повышенная иммунореактивность пациента. В качестве триггерного механизма могут выступать вирусные инфекции, лекарственные препараты и факторы окружающей среды. Однако, согласно теории развития аутоиммунных заболеваний при АИГ свойственно появление (или постоянное присутствие) «запретных клонов» [6-8].

АИГ может протекать бессимптомно или присутствовать в разных формах от субклинического заболевания до острой печеночной недостаточности и терминальной стадии заболевания печени [9, 10].

Наиболее полные рекомендации по клинико-лабораторной диагностике и лечению АИГ представлены в опубликованном Европейской ассоциацией по изучению печени (EASL) в 2015 г. обзоре, а также рекомендациях AASLD 2019 г., в которых имеет место небольшой по объему материал, касающийся морфологической диагностики АИГ, без иллюстраций, отсутствует раздел «этиология АИГ» [11].

Существующие классификации подразделяют АИГ на типичный и атипичный. К вариантам атипичного АИГ относят перекрестные синдромы, дополнительно включающие признаки первичного билиарного цирроза (ПБЦ), первичного склерозирующего холангита (ПСХ), поражения печени, индуцированные вирусами, лекарствами, иммунодефицитами, метаболическими нарушениями [12].

На наш взгляд, несмотря на множество вариантов АИГ, полагаем, что в первый раздел классификации должны быть включены этиология и происхождение АИГ, как это представлено в классификациях большинства болезней с установленной и неустановленной этиологией [13].

\section{Классификация АИГ}

I. По этиологии и происхождению:

1. этиология не установлена:

1.1 первичный вариант АИГ - наличие классических клинико-лабораторных и морфологических маркеров АИГ I, II, III типов;

2. этиология установлена (ассоциированная с разными причинами):

2.1 вторичный вариант - наличие классических маркеров АИГ и доказательств воздействия на печень токсических фракторов, лекарств, вирусов, метаболических, иных причин;

2.2 вторичный вариант (перекрестный) - наличие классических маркеров АИГ и признаков синдрома внутрипеченочного холестаза и/или поражения билиарного тракта: АИГ+ПБЦ, АИ-

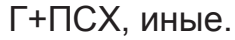

II. По выявлению аутоиммунных антител [14-16]:

I тип: антинуклеарные антитела (ANA) - y
70-80\% пациентов; антигладкомышечные антитела (SMA) у 50-70\%, возможно сочетание ANA и SMA; антитела к растворимому печеночному и печеночно-панкреатическому антигену (анти-SLA и анти-LP), антитела к цитоплазме нейтрофрилов (pANCA), ассоциация с HLA DR3, DR4 и DR13.

II тип: антитела к микросомам печени и почек 1-го типа (анти-LKM-I), у 100\% пациентов, антитела к цитозольному антигену печени (анти-LC1), редко анти-LKM3; ассоциация с HLA DR3 и DR7.

III тип: анти-SLA/анти-LP; часто выявляются ASMA, ревматоидный фактор, антимитохондриальные антитела (AMA), антитела к антигенам печеночной мембраны (анти-LMA), часто определяются антитела к двухцепочечной ДНК (Ro52). В последнее время существование АИГ III типа ставится под сомнение; предлагается рассматривать его не как самостоятельную форму, а как частный случай АИГ I типа.

III. По клиническим проявлениям, течению и ответу на глюкокортикостероиды (ГКС) [14-16]:

АИГ І типа более частый (около 90\%), чаще развивается у женщин в возрасте от 10 до 20 лет и после 50 лет, имеет положительный ответ на иммуносупрессивную терапию с достижением стойкой ремиссии до $20 \%$ случаев, даже после отмены ГКС. При отсутствии лечения в течение 3 лет формируется цирроз печени.

АИГ II типа развивается в 10-15\% случаев АИГ, преимущественно в детском возрасте, характеризуется высокой биохимической активностью и резистентностью к иммуносупрессии; при отмене ГКС часто наступает рецидив; цирроз печени развивается в 2 раза чаще, чем при АИГ । типа.

АИГ III типа рассматривается как вариант 1-го типа АИГ, протекает более тяжело и нуждается в иммуносупрессии на протяжении всей жизни у большинства пациентов. В то же время обоснованность данного деления АИГ на подтипы в настоящее время служит предметом дискуссий [17].

\section{АУТОИММУННЫЙ ГЕПАТИТ, ПЕРВИЧНЫЙ}

Морфология. Морфологические признаки АИГ, представленные AASLD (2019), характеризуются следующими изменениями: интерфейсный гепатит умеренной или высокой активности, без лобулярного гепатита, при котором поражаются гепатоциты перипортальной зоны (рис. 2, 3); центролобулярные (в 3-й зоне ацинуса) некрозы, без поражений билиарной системы (рис. $4,5)$; лимфоплазмоцитарная инфильтрация; портальный мононуклеарный и плазмоклеточный инфильтрат; формирование гепатоцеллюлярной розетки из группы регенерирующих гепатоцитов; эмпериполез - одна клетка «вдавливается» в соседнюю клетку, причем обе сохраняют 
свою структуру и функции); отек гепатоцитов и/или пикнотический некроз гепатоцитов; в инфильтрате могут присутствовать эозинофилы; ступенчатые, мостовидные, мультилобулярные некрозы (рис. 6, 7, 9).

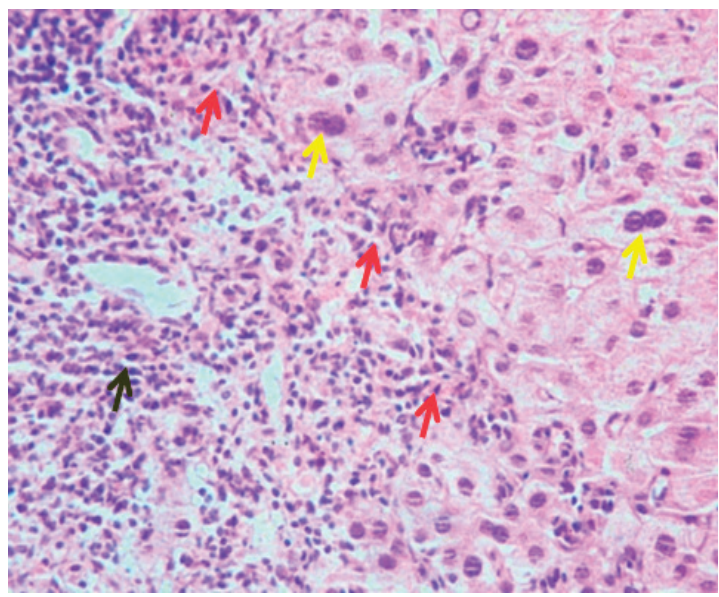

Рисунок 2. - АИГ, интерфрейсный: воспалительный инфильтрат из лимфоцитов, гистиоцитов и большого количества плазмоцитов в портальном тракте (черная стрелка) и некротизированной перипортальной зоне (красные стрелки); дисрегенераторные изменения с образованием значительного количества двуядерных клеток (желтые стрелки). Окр.: гематоксилином и эозином. ×400 Figure 2. - AlH, interface: inflammatory infiltrate from lymphocytes, histiocytes and a large number of plasma cells in the portal tract (black arrow) and necrotic periportal zone (red arrows); dysregenerative changes with the formation of a significant number of binucleated cells (yellow arrows). Coloring: hematoxylin and eosin. $\times 400$

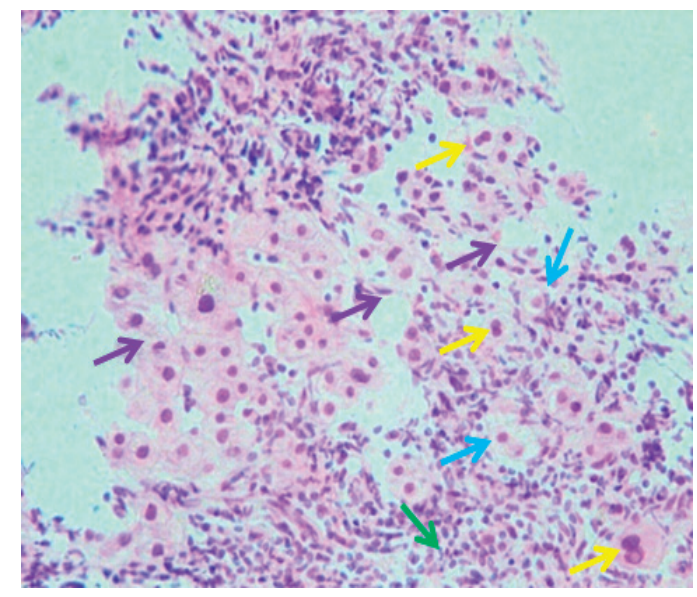

Рисунок 3. - АИГ, интерфейсный: дискомплексация балок на периферии портального тракта (фиолетовые стрелки); в сохранившихся гепатоцитах гидропическая дистрофия и некробиоз (синие стрелки); плазмоциты расположены по краю инфильтрата на границе с неизмененной тканью печени (зеленая стрелка); двуядерные гепатоциты (желтые стрелки). Окр.: гематоксилином и эозином. ×400 Figure 3. - AlH, interface: discomplexation of beams at the periphery of the portal tract (purple arrows); in the preserved hepatocytes, hydropic degeneration and necrobiosis (blue arrows); plasma cells are located along the edge of the infiltrate on the border with unchanged liver tissue (green arrow); binucleated hepatocytes (yellow arrows). Coloring: hematoxylin and eosin. $\times 400$

Для постановки диагноза существенное значение имеет наличие большого количества плазмоцитов (рис. 2, 3) и та или иная степень фиброза [18].

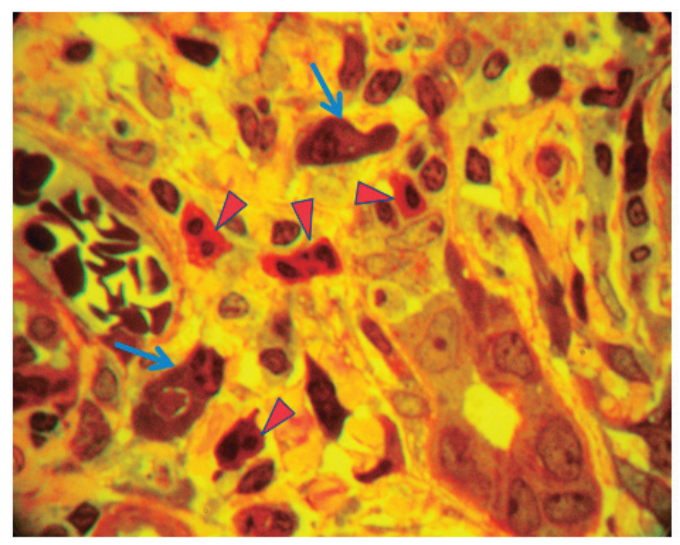

Рисунок 4. - АИГ: нейтрофилы (красные наконечники стрелок) и плазматические клетки (синие стрелки) в инфильтрате портальной зоны. Полутонкий срез. Окраска: азур-осн. фуксин. $\times 1000$

Figure 4. - AlH: neutrophils (red arrowheads) and plasma cells (blue arrows) in the infiltrate of the portal zone. Semi-thin cut. Coloring: azurebasic. magenta. $\times 1000$

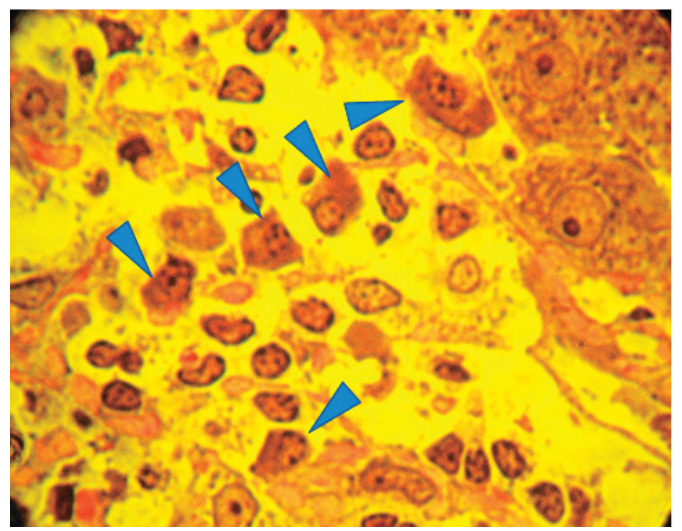

Рисунок 5. - АИГ: кластер плазматических клеток в просвете синусоида (синие наконечники стрелок). Полутонкий срез. Окраска: азур-осн. фруксин. ×1000

Figure 5. - AlH: a cluster of plasma cells in the lumen of a sinusoid (blue arrowheads). Semi-thin cut. Coloring: azure-basic. magenta. $\times 1000$

Большинство специалистов считают, что морфологическая картина АИГ характерна и даже патогномонична, хотя для правильной диагностики необходимы данные клинико-биохимических исследований, данные об аутоантителах и аномальных уровнях глобулинов в сыворотке крови [19].

Плазматические клетки обычно скапливаются по краю воспалительного инфильтрата со стороны неизмененной или малоизмененной ткани печени (рис. 3-7), а также определяются внутри дольки, хотя их малочисленность в воспалительном инфильтрате (34\% всех случаев) не препятствует установлению диагноза.

Характеристики гистологически атипичного АИГ впервые описаны с использованием названия центрилобулярный зональный некроз (CZN) и включали выраженный сливной некроз в зоне 3 с относительным вовлечением портальной области [20]. 
Другие авторы описали CZN как выраженный сливной некроз в зоне 3 с сохранением портальной области [21]. Однако типичный CZN и значительный интерфейсный гепатит могут одновременно быть в одном и том же образце биопсии печени (рис. 8, 9) [22].

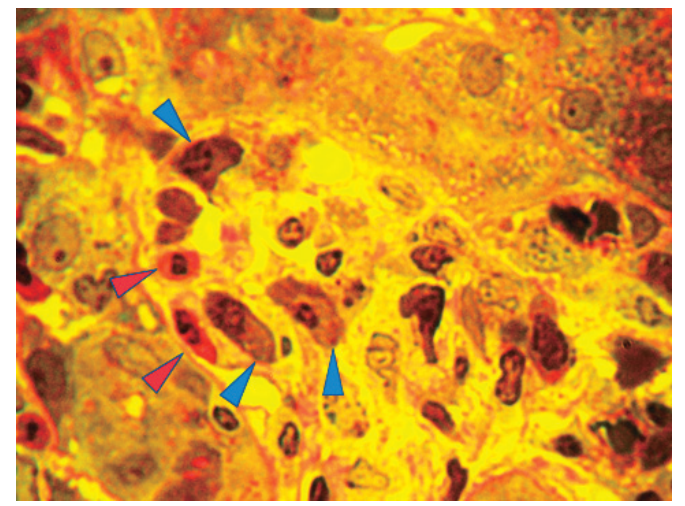

Рисунок 6. - АИГ: ступенчатый (частичный) некроз; инфильтрация в паренхиму: нейтрофрилы (красные стрелки), плазмоциты (синие стрелки) и лимсооциты. Полутонкий срез. Окраска: азур-осн. фруксин. $\times 1000$

Figure 6. - AlH: stepwise (partial) necrosis; infiltration into the parenchyma: neutrophils (red arrows), plasma cells (blue arrows) and lymphocytes. Semi-thin cut. Coloring: azure-basic. magenta. $\times 1000$

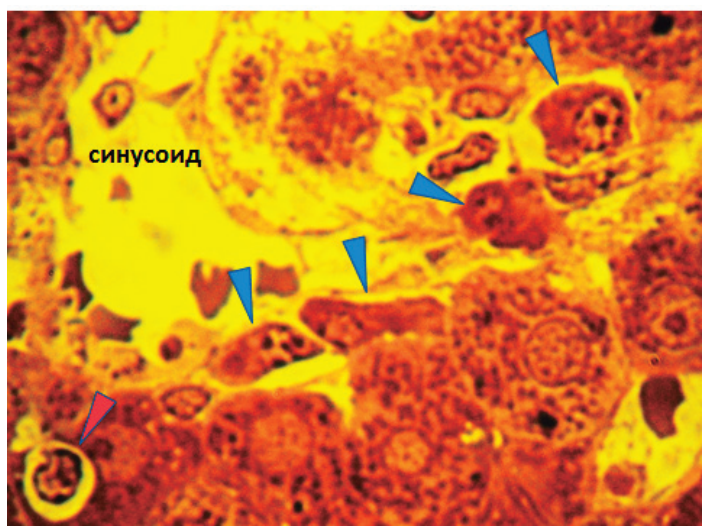

Рисунок 7. - АИГ: скопление плазматических клеток (синие стрелки) со стороны малоизмененной ткани печени. ЦТЛ (красная стрелка). Полутонкий срез. Окраска: азур-осн. фуксин. $\times 1000$

Figure 7. - AlH: an accumulation of plasma cells (blue arrows) from the side of little changed liver tissue. CTL (red arrow). Semi-thin cut. Coloring: azure-basic. magenta. $\times 1000$

Характеристики гистологически атипичного АИГ впервые описаны с использованием названия центрилобулярный зональный некроз (CZN) и включали выраженный сливной некроз в зоне 3 с относительным вовлечением портальной области [20].

Другие авторы описали CZN как выраженный сливной некроз в зоне 3 с сохранением портальной области [21]. Однако типичный CZN и значительный интерфейсный гепатит могут одновременно быть в одном и том же образце биопсии печени (рис. 8, 9) [22].

В составе инфильтрата выявлялись большие гранулярные лимфоциты (БГЛ) или РІТ-клетки (ямочные), непосредственное участие которых доказано в апоптозе гепатоцитов (рис. 10, 11).

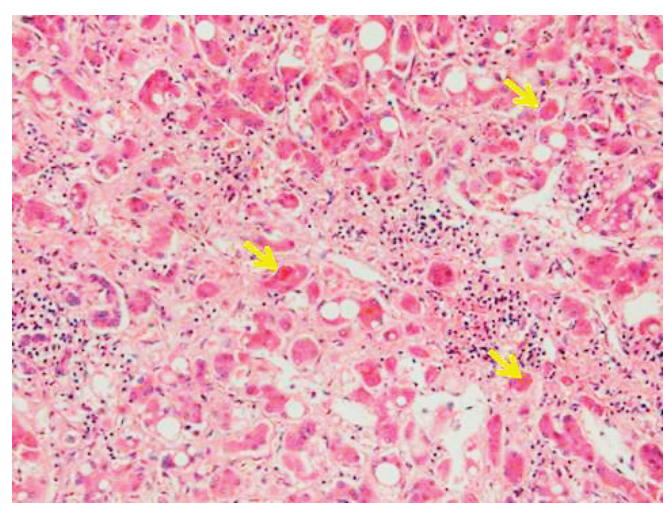

Рисунок 8. - АИГ: сливной (коагуляционный) некроз 3 и 2 зон печёночной дольки (желтые стрелки), очаговаяжироваядистрофия гепатоцитов; умеренно выраженная воспалительнаяинфильтрация. Окраска:гематоксилиномиэозином. ×100 Figure 8. - AlH: confluent (coagulation) necrosis of 3 and 2 zones of the hepatic lobule (yellow arrows), focal fatty degeneration of hepatocytes; moderately pronounced inflammatory infiltration. Coloring: hematoxylin and eosin. $\times 100$

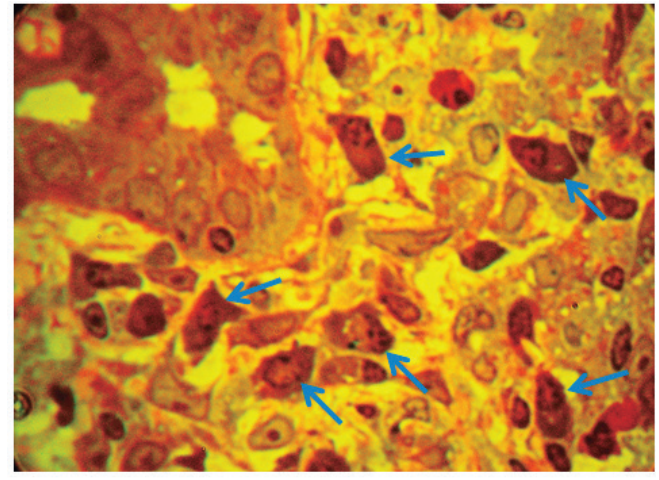

Рисунок 9. - АИГ: кластер плазматических клеток (синие стрелки). Полутонкий срез. Окраска: азур-осн. фуксин. $\times 1000$ Figure 9. - AlH: a cluster of plasma cells (blue arrows). Semi-thin cut. Coloring: azure-basic magenta. $\times 1000$

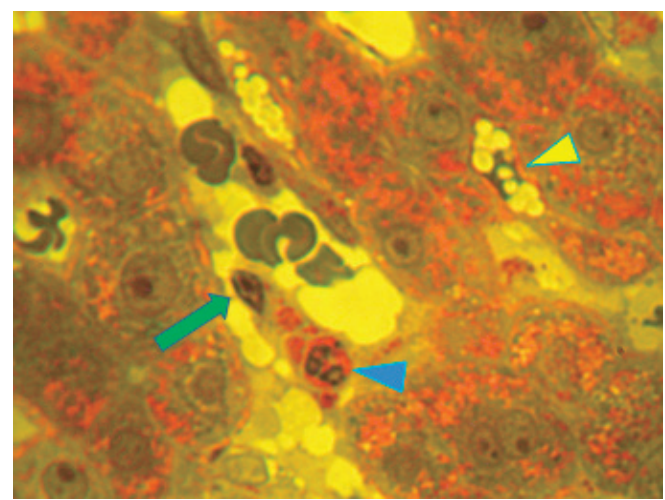

Рисунок 10. -АИГ:БГЛ(зеленая стрелка), цитоплазма которого поляризована и контактирует с цитоплазмой сегментоядерной клетки (синий наконечник), липоцит-желтыйнаконечник. Полутонкий срез. Окраска:азур-осн. фуксин. $\times 1000$ Figure 10. - AlH: BGL (green arrow), the cytoplasm of which is polarized and in contact with the cytoplasm of the segmented cell (blue tip), lipocyte - yellow tip. Semi-thin cut. Coloring: azure-basic. magenta. $\times 1000$

Таким образом, гистологически атипичный АИГ можно разделить на два типа: CZN со щадящим интерфейсным гепатитом и CZN со значительным интерфейсным гепатитом (рис. 12-13). 


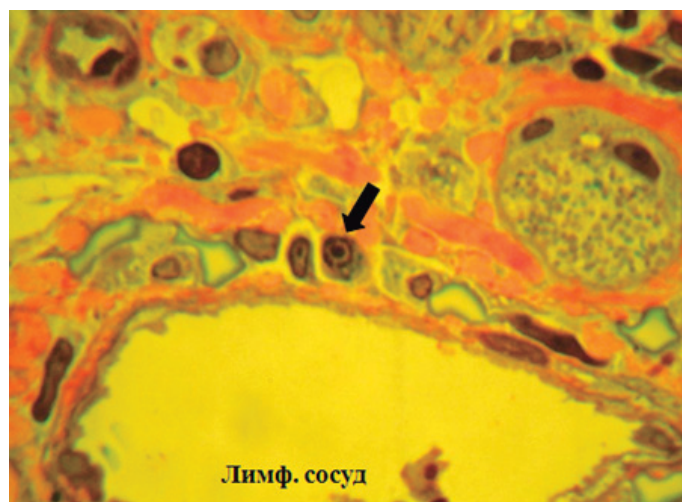

Рисунок 11. - АИГ: БГЛ лимфроцит (стрелка) в неактивированном состоянии в тесном контакте с базальной мембраной крупного лимфатического сосуда. Полутонкий срез. Окраска: азур-осн. ффуксин. $\times 1000$ Figure 11. - AlH: BGL lymphocyte (arrow) in an inactivated state in close contact with the basement membrane of a large lymphatic vessel. Semithin cut. Coloring: azure-basic. magenta. $\times 1000$

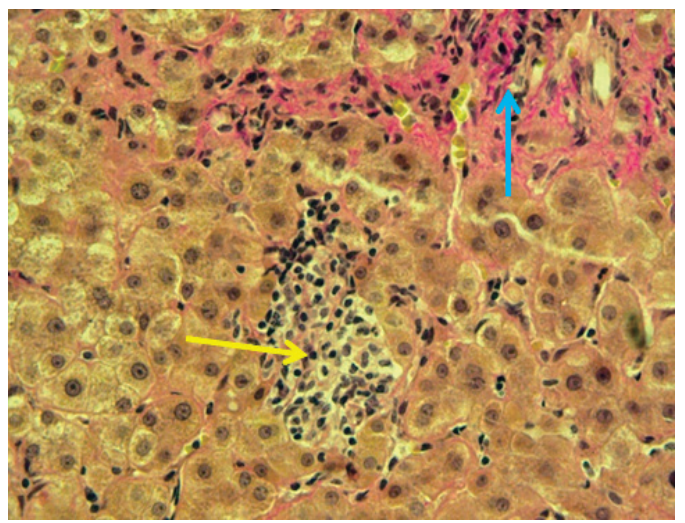

Рисунок 12. - АИГ: CZN со щадящим интерфейсным гепатитом): иентролобулярный очаговый некроз гепатоцитов и воспалительный инфильтрат из лимфооцитов, гистиоцитов и небольшого количества плазматических клеток (желтая стрелка); в портальном тракте (синяя стрелка) фриброз и слабо выраженная воспалительная инфильтрация. Окр.: пикрофруксином по Ван-Гизону. х400 Figure 12 - AlH: CZN with sparing interface hepatitis): centrilobular focal necrosis of hepatocytes and inflammatory infiltrate from lymphocytes, histiocytes and a small number of plasma cells (yellow arrow); in the portal tract (blue arrow) fibrosis and mild inflammatory infiltration. Okr .: picrofuchsin according to Van-Gieson. $\times 400$

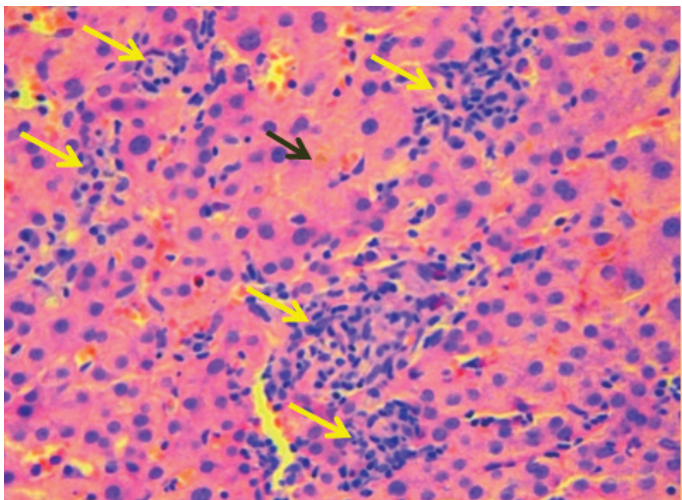

Рисунок 13. - АИГ: CZN с резко выраженным интерфейсным гепатитом: множественные крупноочаговые панлобулярные сливающиеся между собой некрозы с резко выраженной воспалительной инфильтрацией (желтые стрелки); внутридольковый холестаз (черная стрелка). Окр.: гематоксилином и эозином. $\times 400$ Figure 13. - AlH: CZN with pronounced interface hepatitis: multiple large-focal panlobular necrosis merging with each other with pronounced inflammatory infiltration (yellow arrows); intralobular cholestasis (black arrow). Environment: hematoxylin and eosin $\times 400$
Фиброз может отсутствовать при легких формах болезни и быть интенсивным при прогрессировании АИГ, связывать портальные и центральные области (мостовидный фриброз) и нарушать архитектонику долей, способствовать появлению регенерирующих узелков и цирроза (рис. 14, 17).

Могут наблюдаться плазмоклеточный инфрильтрат, розеткообразная структура гепатоцитов и многоядерные гигантоциты (рис. 14, 15)

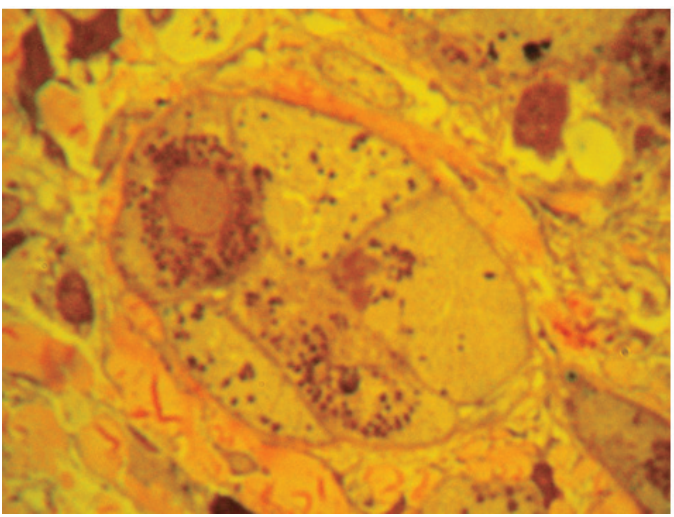

Рисунок 14. - АИГ: розетка гепатоцитов, окруженная фиброзной тканью; изолированные капсулой клетки, находятся на разных стадиях дегенерации. Полутонкий срез. Окраска: азур-осн. фуксин. $\times 1000$

Figure 14. - AlH: rosette of hepatocytes surrounded by fibrous tissue, cells isolated by the capsule are at various stages of degeneration. Semithin cut. Coloring: azure-basic. magenta. $\times 1000$

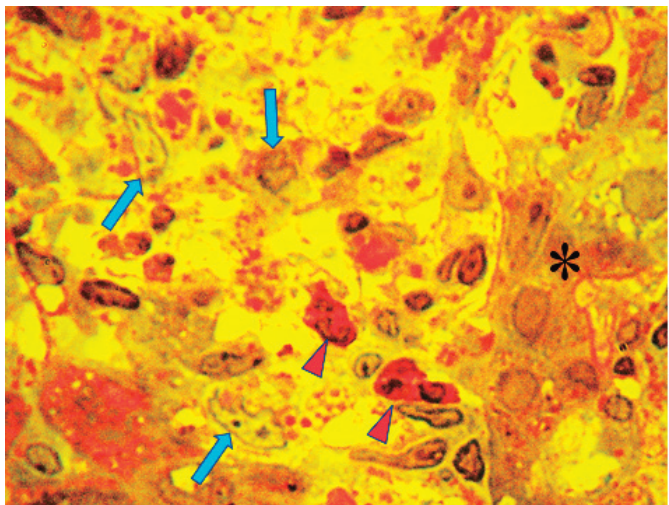

Рисунок 15. - АИГ: фрагмент перипортального инфильтрата, в котором наблюдается лизис гепатоцитов (звездочка) ферментами разрушающихся нейтрофилов (красные наконечники) и макрофрагов (синие стрелки); Полутонкий срез. Окраска: азур-осн. фуксин. $\times 1000$ Figure 15. - AlH: a fragment of the periportal infiltrate, in which lysis of hepatocytes (asterisk) is observed by enzymes of disintegrating neutrophils (red tips) and macrophages (blue arrows); Semi-thin cut. Coloring: azure-basic. magenta. $\times 1000$

Изменение желчных протоков при АИГ наблюдают приблизительно у 25\% пациентов, однако они, как правило, слабо выражены (рис. $16,17)$. Выраженные билиарные изменения свидетельствуют об альтернирующем течении заболевания и должны вызывать подозрение на первичный склерозирующий холангит (ПСХ) или перекрестные синдромы. 


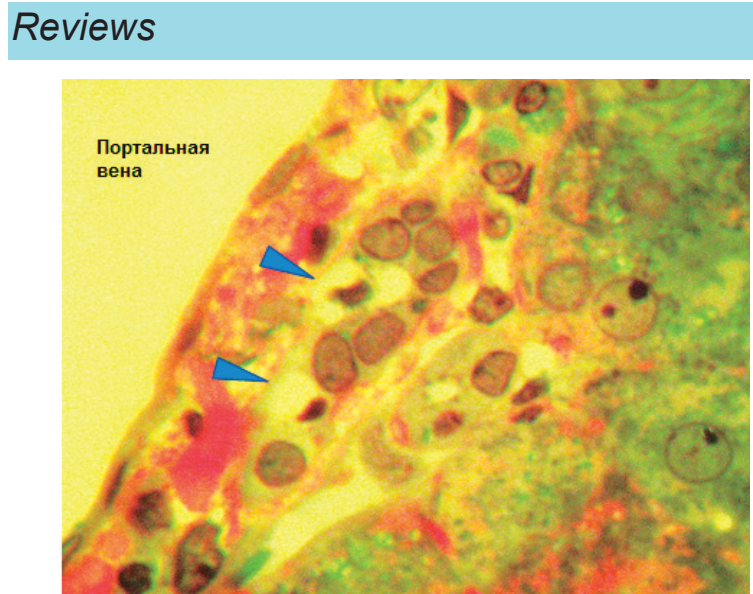

Рисунок 16. - АИГ, вторичный: апоптоз холангиоцитов (синие наконечники). Полутонкий срез. Окраска: азур-осн. фоксин. $\times 1000$

Figure 16. - AlH, secondary: cholangiocyte apoptosis (blue tips). Semithin cut. Coloring: azure-basic. magenta. $\times 1000$

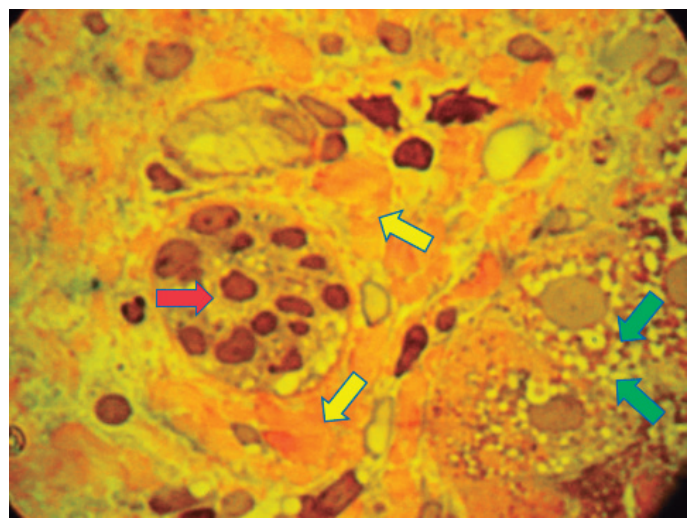

Рисунок 17. - АИГ: перидуктулярный фриброз (желтые стрелки), гидропическая дистрофия гепатоцитов (зеленые стрелки); желчный проток - красная стрелка. Полутонкий срез. Окраска: азур-осн. ффуксин. ×1000 Figure 17. - AlH: periductular fibrosis (yellow arrows), hydropic degeneration of hepatocytes (green arrows); bile duct - red arrow. Semithin cut. Coloring: azure-basic. magenta. $\times 1000$

Гистологически атипичный АИГ описан у японских пациентов и иммуногенетически отличается от типичного АИГ. CZN может быть обнаружен в биоптатах печени пациентов, у которых развился АИГ более 6 месяцев тому назад. Кроме того, CZN может сосуществовать со значительным портальным фриброзом при хроническом АИГ [23].

Установлено, что маркер HLA-DR4 - резистентный, тогда как DR9 - чувствительный HLA-феннотип гистологически атипичного АИГ. Это убедительно свидетельствует о том, что гистологически атипичный АИГ не является временным гистологическим признаком очень раннего типичного АИГ, а служит признаком отличительного подтипа АИГ [20].

В целом прогноз гистологически атипичного АИГ хороший, а реакция на иммуносупрессию - отличная [24]. Однако в ряде случаев атипичный АИГ может быстро трансформироваться в острую печёночную недостаточность, которая нередко становится причиной смерти [23]. В таких случаях возникают обширные некрозы гепатоци- тов, что является морфологическим субстратом гепаторрагии.

Специалисты по электронной микроскопии в некоторых исследованиях выявленные стекловидные капельки гиалина в цитоплазме клеток Купфера (КК) обозначили как новый ультраструктурный признак АИГ у детей $[25,26]$. Однако наши исследования согласуются с выводами других авторов, которые считают, что появление капель гиалина в КК не характерно для пациентов с АИГ (рис. 18, 19) [27].

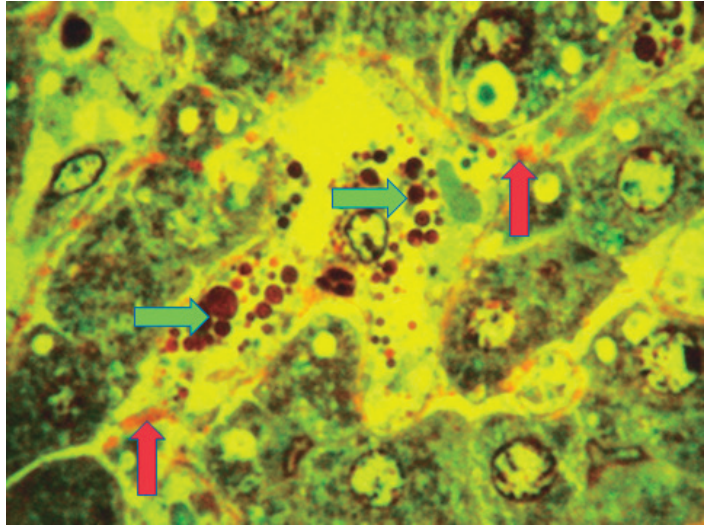

Рисунок 18. - АИГ: в цитоплазме активированной КК много включений разного размера (зеленые стрелки). Перисинусоидальная соединительная ткань окрашена в красный цвет. Полутонкий срез. Окраска: азур-осн. фруксин. ×1000 Figure 18. - AlH: in the cytoplasm of activated CC there are many inclusions of various sizes (green arrows). The perisinusoidal connective tissue is colored red. Semi-thin cut. Coloring: azure-basic. magenta. $\times 1000$

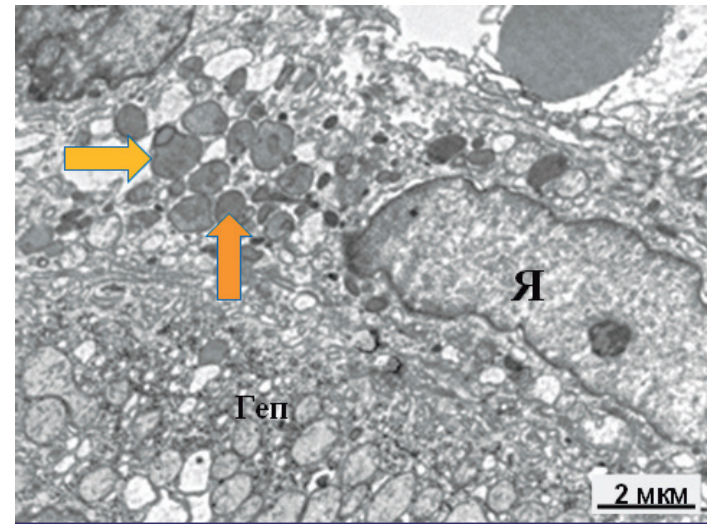

Рисунок 19. - АИГ: на электронограмме в цитоплазме КК скопление (кластер) крупных гранул неправильной фоормы (стрелки). Я - ядро КК, Геп - фрагмент цитоплазмы гепаmouиma.

Figure 19. - AIH: on the electron diffraction pattern in the cytoplasm of the CC, an accumulation (cluster) of large irregularly shaped granules (arrows). Я - is the nucleus of KК, Геп - is a fragment of the cytoplasm of the hepatocyte

В процессе исследования состояния синусоидальных эндотелиальных клеток (LSEC) печени в морфогенезе АИГ у детей показаны изменения LSEC, от отека до некроза, что демонстрирует их важную роль в морфогенезе и прогрессировании АИГ у детей. Часто повреждение LSEC сочеталось с активированными КК (рис. 20), фриброгенезом и фриброзом, но не циррозом, сопро- 
вождающимся появлением переходных звездчатых клеток печени. Несмотря на то, что у $50 \%$ детей с АИГ синусоидальные сосуды претерпевали преобразование прерывистого эндотелия в непрерывный с признаками дефенестрации, истинная базальная мембрана под ними не формировалась. Этот факт, по мнению авторов, указывает на некоторые регенеративные способности LSEC и обратимость поражения [28].

В наших наблюдениях нашло подтверждение мнение авторов о сочетании повреждения LSEC и активации КК при АИГ (рис. 20).

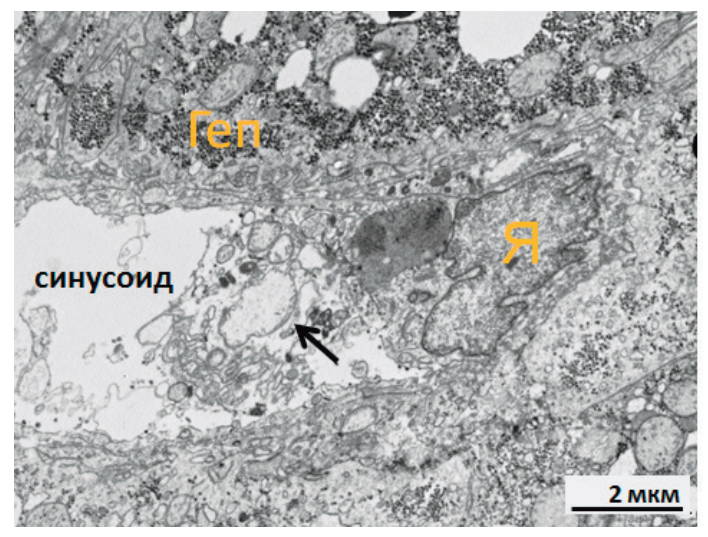

Рисунок 20. - АИГ: разрушение эндотелиальной клетки синусоида (LSEC): деформированное ядро (Я) $c$ глубокими вырезками; разбухшая митохондрия с частично лизированными кристами, (стрелка); крупная неправильной формы гранула вблизи ядра Figure 20. - AlH: sinusoidal endothelial cell destruction (LSEC): deformed nucleus (Я) with deep notches; swollen mitochondrion with partially lysed cristae (arrow); large irregularly shaped granule near the nucleus

В одной из работ представлены сравнительные гистологические исследования, проведенные у 50 пациентов с ХГС и у 21 пациента с АИГ по 19 разным гистологическим признакам. Результаты показали, что средний возраст пациентов с ХГС был на 10 лет выше, чем при АИГ (64 года и 36 лет). Цирроз чаще диагностирован при ХАГ (90\%), чем при ХГС (58\%). При АИГ чаще отмечены тяжелый лобулярный некроз и воспаление (76\% против 38\% при ХГС), частичный некроз (81 и 10\%), многоядерные гепатоциты (29 и $6 \%)$, обширные области паренхиматозного коллапса (76 и 6\%). При ХГС отмечены следующие особенности: повреждение желчных протоков (91\% против 40\% при ХАГ), потеря желчных протоков (91 и 20\%), стеатоз (72 и 20\%), агрегация лимфоидных клеток (фолликулов) внутри портальных трактов (49 и 10\%). Авторы считают, что указанные морфологические признаки вместе с серологическими критериями важны для дифференциации ХГС с АИГ, который гистологически является более агрессивным заболеванием [29].

Морфологические изменения в печени пациентов с АИГ соответствует тяжелому хроническому гепатиту, при котором активность процесса выражена неравномерно, а некоторые участки могут быть неизмененными.
В зоне 1 отмечаются клеточные инфильтраты, состоящие преимущественно из лимфоцитов и плазматических клеток, которые проникают между гепатоцитами (рис. 21-22).

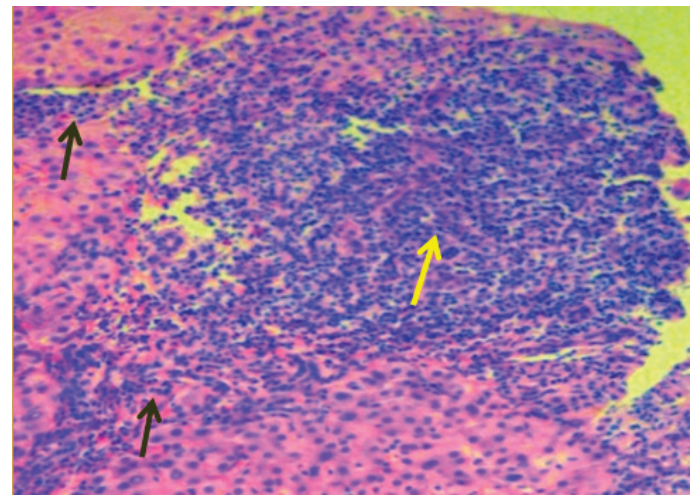

Рисунок 21. - АИГ: CZN с выраженным интерфейсным гепатитом): резко выраженная лимфоидно-гистиоцитарная и плазмоклеточная инфильтрация портального тракта и 1 зоны дольки (черные стрелки) с формированием зародышевого центра в портальном тракте (желтая стрелка). Окр.: гематоксилином и эозином. $\times 100$ Figure 21. - AlH: CZN with severe interface hepatitis): pronounced lymphoid-histiocytic and plasma cell infiltration of the portal tract and 1 zone of the lobule (black arrows) with the formation of the embryonic center in the portal tract (yellow arrow). Coloring: hematoxylin and eosin. $\times 100$

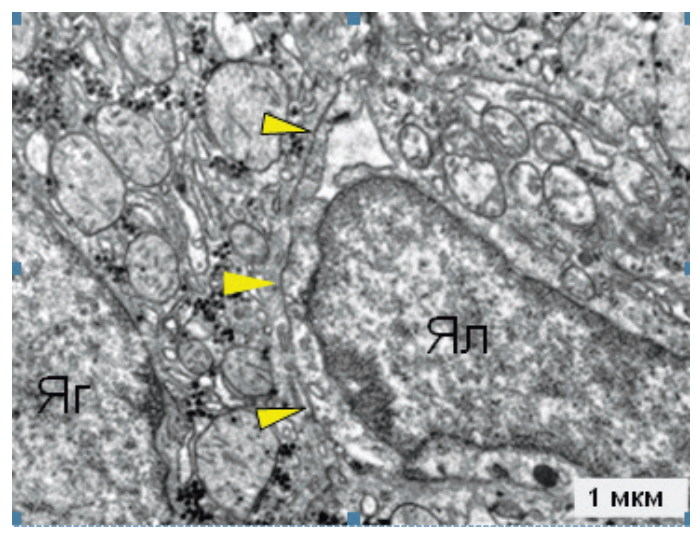

Рисунок 22. - АИГ: эмпериполез и пенетрация: внедрение лимфоцита между гепатоцитами. Наконечниками стрелок обозначен контакт мембран гепатоцита и лимфоцита. Яг - ядро гепатоцита, Ял - ядро лимсооцита Figure 22. - AlH: empiripolysis and penetration: the introduction of a lymphocyte between hepatocytes. The arrowheads indicate the contact of the hepatocyte and lymphocyte membranes. Я己 - is the nucleus of the hepatocyte, Ял - is the nucleus of the lymphocytea

По результатам одной из публикаций, эмпериполез (рис. 23) выявлен в 57 (65\%) случаях хронического АИГ, а также имел место в 10 (50\%) случаях ПБЦ (ПБХ) (p=0,31) и в 10 (77\%) случаях аутоиммунного острого гепатита $(p=0,53)$. Розетки присутствовали в 29 (33\%) случаях в группе с АИГ, что было близко к аналогичному признаку $(38 \%)$ при неаутоиммунном гепатите $(p=0,78)$. Розетки не были идентифицированы ни в одном случае первичного желчного холангита. Эмпериполез и розетки выявлены в 23 (26\%) случаях АИГ и в 4 (31\%) случаях аутоиммунного острого гепатита $(p=1,0)$ [30]. 


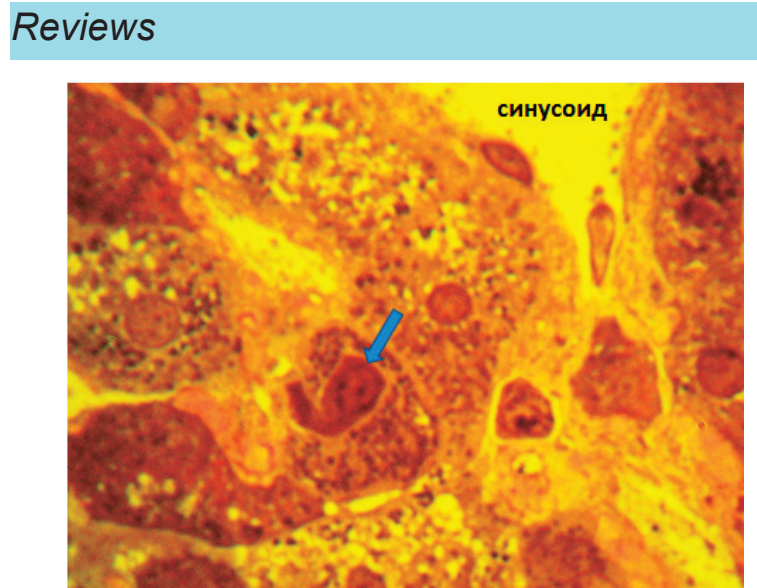

Рисунок 23. - АИГ: эмпериполез плазматической клетки (синяя стрелка) в цитоплазму гепатоцита. Полутонкий срез. Окраска: азур-осн. ффуксин. $\times 1000$ Figure 23. - AlH: empiripolysis of the plasma cell (blue arrow) into the cytoplasm of the hepatocyte. Semi-thin cut. Coloring: azure-basic. magenta. $\times 1000$

Усиленное формирование перегородок изолирует группы печёночных клеток в виде розеток. Жировая дистрофия при АИГ отсутствует, встречаются зоны коллапса. В паренхиму внедряется соединительная ткань, быстро формируя цирроз макронодулярного типа. Со временем активность гепатита снижается, клеточная иноильтрация и число ступенчатых некрозов уменьшаются, фриброзная ткань становится более плотной. В большинстве случаев на периферии узлов выявляются зоны ступенчатых некрозов и формирование розеток (рис. 14).

В начале заболевания цирроз развивается лишь у трети пациентов, обычно выявляется через 2 года после его дебюта. Повторяющиеся эпизоды некроза с последующим коллапсом стромы и фиброзом усугубляют цирроз. Со временем печень становится маленькой и подвергается грубым цирротическим изменениям [31].

\section{АУТОИММУННЫЙ ГЕПАТИТ, ВТОРИЧНЫЙ}

Морфология. Вторичное происхождение АИГ доказывается наличием документального подтверждения фактов воздействия на печень токсических агентов в прошлом и констатации индуцированного гепатотоксинами хронического поражения печени. Дополнительные критерии исключение другой этиологии при обследовании и наличие иммунологических маркеров АИГ.

Приводим конкретный пример вторичного АИГ у пациента М., 64 лет, сельского жителя. До выхода на пенсию в течение 20 лет имел прямой контакт с пестицидами на складе удобрений. Вредные привычки отсутствуют, маркеры вирусных гепатитов отрицательные, лекарства не употреблял. Жалобы на слабость, утомляемость, тяжесть в правом подреберье. АсАТ и АлАТ более 10 норм, ЩФ и ГГТП - более 5 норм. Фиброэластометрия: FIII-IV. ANA, анти-SLA и анти-LP - положительные.

У пациента выявлены морфологические признаки АИГ: перипортальный гепатит с плотными плазмоцитарными и лимфоидно-гистиоцитарными инфильтратами, образование гепатоцитарных розеток, эмпериполез, гидропическая дистрофия и/или колликвационный или коагуляционный некроз гепатоцитов (рис. 24, 25) [32].

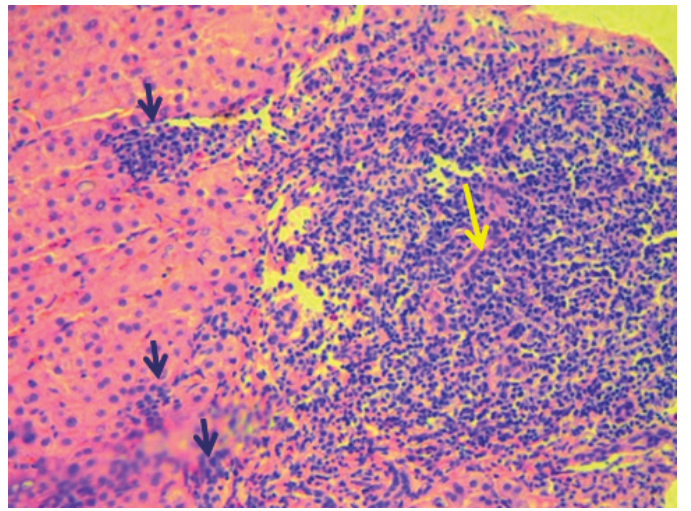

Рисунок 24. - АИГ, вторичный: в портальном тракте (желтая стрелка) и разрушающейся перипортальной зоне (черные стрелки) - воспалительный инфильтрат из лимфоцитов, гистиоцитов и большого количества плазматических клеток; плазмоциты преимущественно располагаются по краю инфильтрата на границе с неизмененной тканью печени. Окраска: гематоксилином и эозином. ×200 Figure 24. - AlH, secondary: in the portal tract (yellow arrow) and the collapsing periportal zone (black arrows) - an inflammatory infiltrate of lymphocytes, histiocytes and a large number of plasma cells; plasma cells are predominantly located along the edge of the infiltrate on the border with unchanged liver tissue. Coloring: hematoxylin and eosin. $\times 200$

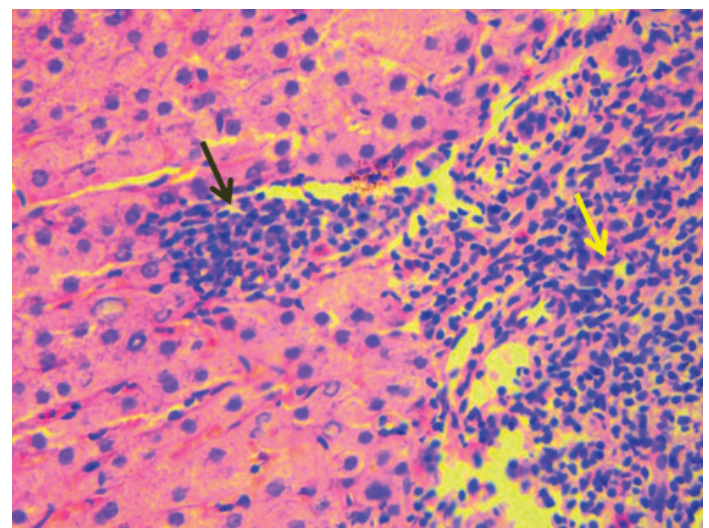

Рисунок 25. - АИГ, вторичный: очаг некроза в перипортальной зоне с резко выраженной лимфоидно-плазмоклеточной инфильтрацией (черная стрелка); выраженная воспалительная инфильтрация портального тракта (желтая стрелка). Окраска: гематоксилином и эозином. ×400 Figure 25. - AlH, secondary: a focus of necrosis in the periportal zone with a pronounced lymphoid-plasma cell infiltration (black arrow); severe inflammatory infiltration of the portal tract (yellow arrow) Coloring: hematoxylin and eosin. $\times 400$

Структура печени была нарушена за счет альтеративных и воспалительных изменений гепатоцитов в портальных трактах, перипортальных зонах и внутри печёночных долек. Портальные тракты инфильтрированы не только лимфоцитами, макрофрагами и фиибобластами, но и большим количеством нейтрофилов и плазматических клеток. Перипортально и внутри долек повсеместно определялся очаговый воспалительный инфильтрат, расположенный на месте погибших гепатоцитов. Нейтрофилы в 
значительном количестве обнаружены и в синусоидах. В паренхиме печени определялись тяжелый лобулярный некроз, ступенчатые и внутридольковые некрозы (рис. 26-29).

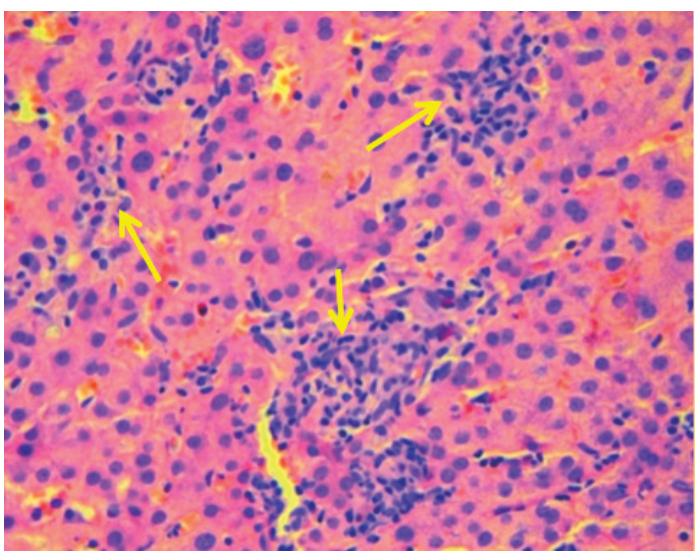

Рисунок 26. - АИГ, вторичный: воспалительный инфильтрат внутри дольки на месте погибших гепатоцитов. Окраска: гематоксилином и эозином. ×400 Figure 26. - AlH, secondary: inflammatory infiltrate inside the lobule at the site of dead hepatocytes. Coloring: hematoxylin and eosin. $\times 400$

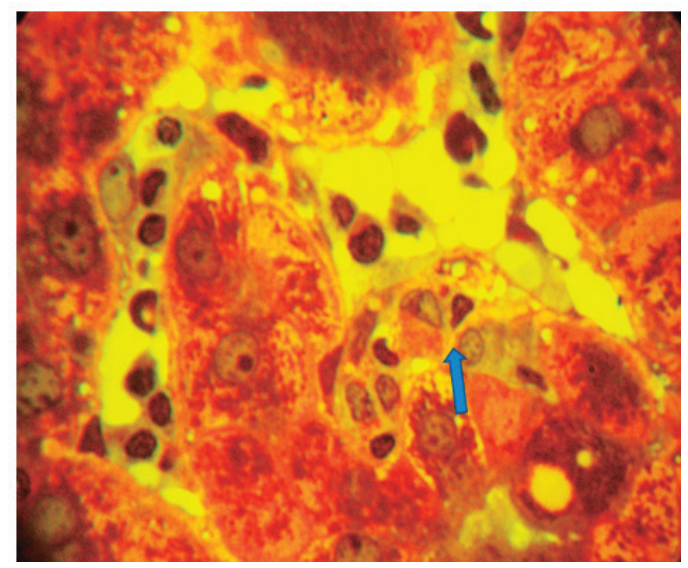

Рисунок 27. - АИГ, вторичный: лимфоцитарная инфильтрация синусоида и разрушение гепатоцитов (стрелка). Полутонкий срез. $\times 1000$

Figure 27. - AlH, secondary: lymphocytic infiltration of the sinusoid and destruction of hepatocytes (arrow). Semi-thin cut. $\times 1000$

В цитоплазме сохранившихся гепатоцитов отмечалась белковая дистрофия; ядра гепатоцитов были разновеликими, местами - с множеством ядрышек; хроматин распределялся неравномерно, местами - пылевидный, конденсирован, ядра представлялись резко гиперхромными, а часть ядер - с признаками кариопикноза (рис. 30, 31).

Апоптозы гепатоцитов не выявлены, что свидетельствовало о том, что нарушение структуры печени обусловлено преимущественно некрозом гепатоцитов и их ускоренным старением (рис. 32, 33).

Кое-где определялся внутриклеточный холестаз (рис. 34).

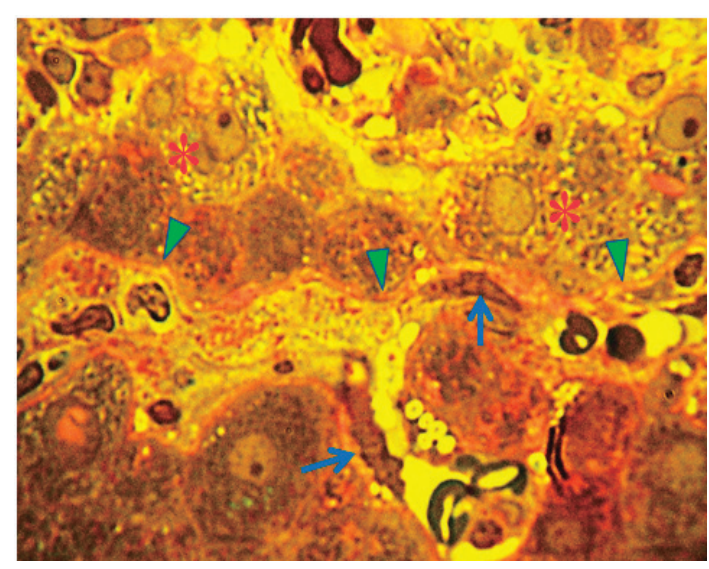

Рисунок 28. - АИГ, вторичный: обтурация КК и лимфоцитами синусоида (зеленые наконечники стрелок), отделенного от перипортального инфильтрата дистрофически измененными гепатоцитами (красные звездочки); синие стрелки - ядра ффибробластов. Полутонкий срез. х1000 Figure 28. - AlH, secondary: obturation of CC and lymphocytes of the sinusoid (green arrowheads), separated from the periportal infiltrate by dystrophic hepatocytes (red asterisks); blue arrows - fibroblast nuclei. Semi-thin cut. $\times 1000$

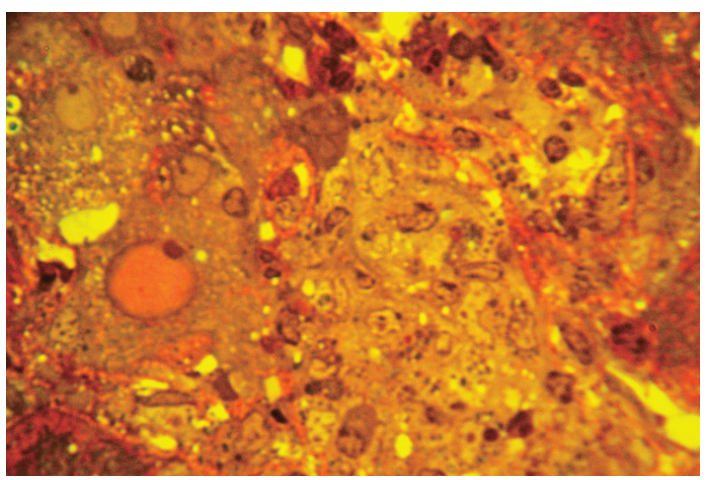

Рисунок 29. - АИГ, вторичный: тяжелый лобулярный некроз в окружении дегенерирующих гепатоцитов паренхимы печёночной ткани. Полутонкий срез. Окраска: азур-осн. фоксин. $\times 800$

Figure 29. - AlH, secondary: severe lobular necrosis surrounded by degenerating hepatocytes of the liver parenchyma. Semi-thin cut. Coloring: azure-basic. magenta. $\times 800$

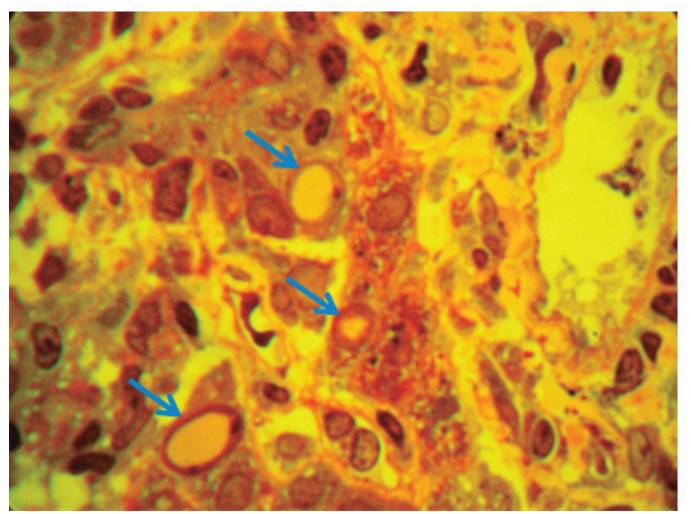

Рисунок 30. - АИГ, вторичный: разрушение гепатоцитов, содержащих кольцевидные ядра (стрелки). Полутонкий срез. $\times 1000$

Figure 30. - AlH, secondary: destruction of hepatocytes containing annular nuclei (arrows). Semi-thin cut. $\times 1000$ 


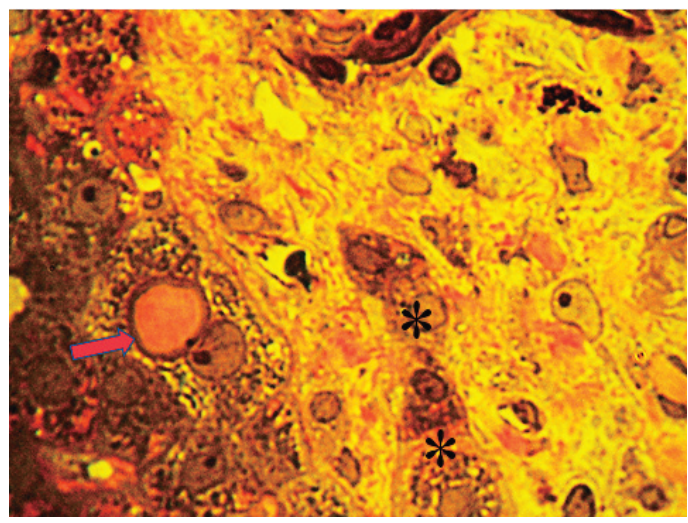

Рисунок 31. - АИГ, вторичный: контакт дистрофически измененного двуядерного гепатоцита с соединительной тканью перипортального инфильтрата, в цитоплазме гепатоцита «полое»ядро (краснаястрелка); черныезвездочки-дегенерирующие гепатоциты. Полутонкий срез. ×1000 Figure 31. - AlH, secondary: contact of a dystrophically altered binuclear hepatocyte with the connective tissue of the periportal infiltrate, in the cytoplasm of the hepatocyte there is a "hollow" nucleus (red arrow); black asterisks - degenerating hepatocytes. Semi-thin cut. $\times 1000$

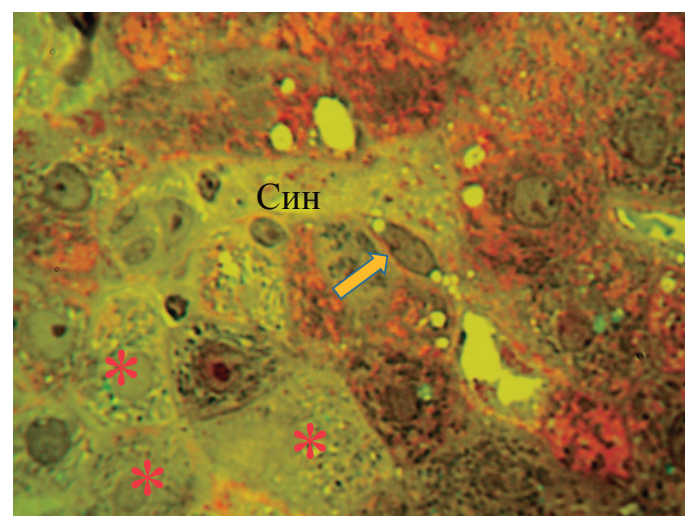

Рисунок 32. - АИГ, вторичный: очаг некробио за гепатоцитов (красные звездочки), из-за обтурации синусоидов. Желтая стрелка - липоцит, теряющий липидные капли, контактирует с КК, ядро которого не попало в срез: в его цитоплазме видны мно гочисленные лизосомы красного цвета. Син - синусоид. Полутонкий срез. Окраска: азур І-основной фруксин. ×1000. Figure 32. - AlH, secondary: focus of necrobiosis of hepatocytes (red asterisks), due to sinusoidal obstruction. Yellow arrow - a lipocyte losing lipid droplets is in contact with CC, the nucleus of which did not get into the cut: numerous red lysosomes are visible in its cytoplasm. Сuн is a sinusoid. Semi-thin cut. Coloring: azure I-basic fuchsin. $\times 1000$

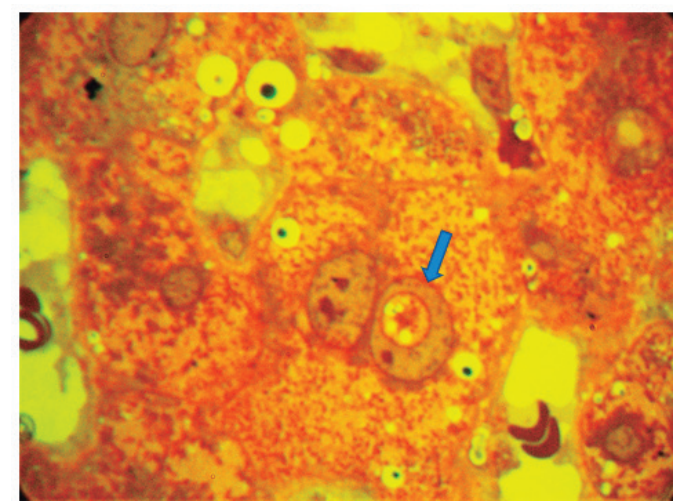

Рисунок 33. - АИГ, вторичный: нарушение структуры ядер в полиплоидном гепатоците (стрелка). Полутонкий срез. $\times 1000$

Figure 33. - AlH, secondary: violation of the structure of the nuclei in a polyploid hepatocyte (arrow). Semi-thin cut. $\times 1000$
Местами встречалось слабовыраженное воспаление желчных протоков портальных трактов, без очевидных признаков их редукции и пролифрерации. Выражена гиперплазия клеток РЭС.

Фиброз умеренно выражен, локализовался преимущественно в портальных трактах, а также перисинусоидально (но неравномерно), а также в виде очажков внутри долек. Обнаружена одна тонкая порто-портальная септа (рис. 35 и 36).

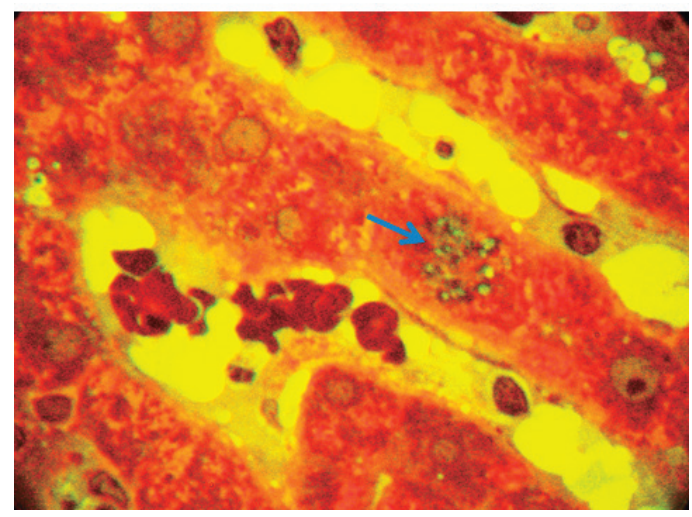

Рисунок 34. - АИГ, вторичный: гепатоцит печёночной пластинки, содержащий капельки желчи (стрелка). ×1000 Figure 34. - AlH, secondary: hepatocyte of the hepatic lamina containing droplets of bile (arrow). $\times 1000$

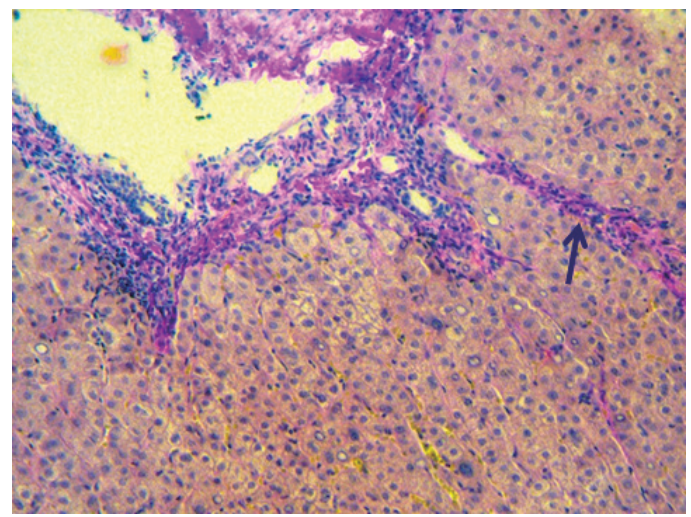

Рисунок 35. - АИГ, вторичный: фриброз в портальном тракте, очаговая капилляризация синусоидов; фррагмент порто-портальной септы (стрелка). Окраска: гематоксилином и эозином. $\times 100$

Figure 35. $-A I H$, secondary: fibrosis in the portal tract, focal capillarization of the sinusoids; fragment of a port-portal septum (arrow). Coloring: hematoxylin and eosin. $\times 100$

Представленные морфологические изменения у пациента М. характерны для вторичного АИГ III типа, высокой степени активности с умеренно выраженным фриброзом и внутрипечёночным холестазом, обусловленного многолетним воздействием на организм пациента токсического фрактора (пестицидов). Аутоиммунный механизм прогрессирования патологии печени после устранения токсического фактора привел к формированию активного гепатита/цирроза печени. Назначение преднизолона в суточной дозе 40 мг в течение 1 месяца не повлияло на снижение активности индикаторных ферментов. Заме- 


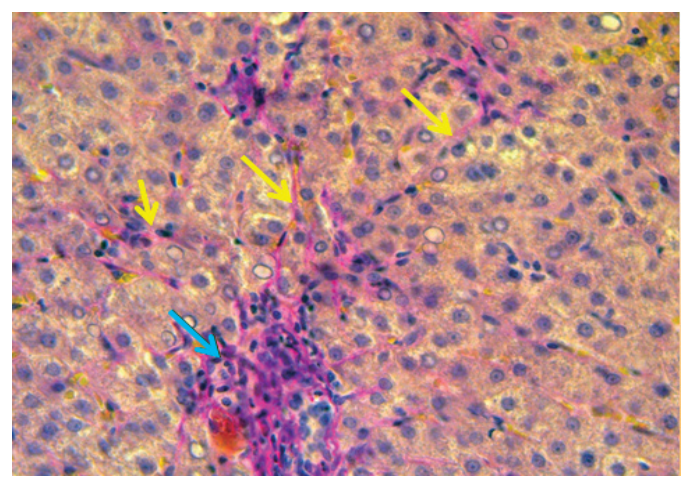

Рисунок 36. -АИГ, вторичный:фриброзвпортальномтракте (синяя стрелка), очаговая капилляризация синусоидов (желтые стрелки). Окраска: гематоксилином и эозином. ×200 Figure 36. - AlH, secondary: fibrosis in the portal tract (blue arrow), focal capillarization of the sinusoids (yellow arrows). Coloring: hematoxylin and eosin. $\times 200$

на преднизолона на азатиоприн привела к снижению активности АИГ (индикаторных фрерментов до субнормальных цифр) и стабилизации состояния. В течение последних двух лет прогрессирования гепатита/цирроза не наблюдается.

\section{Выводы}

Убедительных морфологических признаков, которые можно было бы назвать патогномонич- ными для АИГ, не существует. Перипортальный гепатит - неспецифический признак, который можно обнаружить у пациентов с лекарственным, вирусным или иммуноопосредованным поражением печени. Такие признаки выраженной воспалительной активности, как панлобулярный гепатит, мостовидный некроз и массивный некроз, встречаются реже и могут наблюдаться при остром поражении печени [33]. Характерная для АИГ гистологическая картина в виде панацинарного гепатита (коллапс паренхимы) часто встречается в биоптатах, взятых в период острого начала заболевания и весьма похожа на лекарственный гепатит [34, 35]. Перицентральный некроз (3 зона Раппапорта) может напоминать начальные стадии острого токсического поражения печени [21].

Гистологические проявления альтеративных изменений, воспалительной активности и тяжести АИГ нередко не соответствуют биохимической активности заболевания [36, 37].

Несмотря на продолжающийся диагностический поиск маркеров АИГ, биопсия печени позволяет получить более объективную диагностическую и прогностическую информацию, а также обосновать тактику лечения [38].

\section{References}

1. Waldenstrom J. The diagnostic importance of ACTH J. Acta Endocrinol. 1950;5(3):235-242. doi: 10.1530/ acta.0.0050235

2. Kunkel HG, Ahrens EH, Eisenmenger WJ, Bongiovanni AM, Slater RJ. Extreme hypergammaglobulinemia in young women with liver disease of unknown etiology. J. Clin. Invest. 1951;30:654.

3. Johnson PJ, McFarlane I.G. Meeting report: Internationa Autoimmune Hepatitis Group. Hepatology. 1993;18(4):9981005. doi: 10.1002/hep.1840180435.

4. Floreani A, Restrepo-Jiménez P, Secchi MF, De Martin S, Leung PSC, Krawitt E, Bowlus CL, Gershwin ME, Anaya J-M. Etiopathogenesis of autoimmune hepatitis. J. Autoimmun 2018;95:133-143. doi: 10.1016/j.jaut.2018.10.020.

5. Autoimmunnyj gepatit [Internet]. Available from: http://doctor-365.net/autoimmunnyj-gepatit/ (Russian).

6. Sucher E, Sucher R, Gradistanac T, Brandacher G, Schneeberger S, Berg T. Autoimmune HepatitisImmunologically Triggered Liver Pathogenesis-Diagnostic and Therapeutic. J. Immunol Res. 2019;2019:9437043. doi: 10.1155/2019/9437043

7. Manns MP, Lohse AW, Vergani D. Autoimmune hepatitis-Update 2015. J. Hepatol. 2015;62(1 Suppl):S100-111. doi: 10.1016/j.jhep.2015.03.005.

8. Patogenez autoimmunnogo gepatita [Internet]. Available from: https://studopedia.ru/13_27301_vopros--patogenez-autoimmunnogo-gepatita.html (Russian).

9. Heneghan MA, Yeoman AD, Verma S, Smith AD, Longhi MS. Autoimmune hepatitis. Lancet. 2013;382(9902):14331444. doi: 10.1016/S0140-6736(12)62163-1.

10. Czaja AJ. Diagnosis and management of autoimmune hepatitis: current status and future directions. Gut Liver. 2016;10(2):177-203. doi: 10.5009/gnl15352.

11. European Association for the Study of the Liver EASL Clinical Practice Guidelines: Autoimmune hepatitis. J. Hepatol. 2015;63(4):971-1004. doi: 10.1016/j. jhep.2015.06.030.

12. Ortega-Alonso A, Andrade RJ. Chronic liver injury induced by drugs and toxins. J. Dig. Dis. 2018;19(9):514-521. doi: 10.1111/1751-2980.12612

13. Malevich K. Autoimmunnyj gepatit (klinika, diagnostika, lechenie) [Internet]. Makhachkala; 2013. Available from: https://pandia.ru/text/80/332/84652.php (Russian).
14. Manns M, Gerken G, Kyriatsoulis A, Staritz M, Meyer zum Büschenfelde $\mathrm{KH}$. Characterization of a new subgroup of autoimmune chronic active hepatitis by autoantibodies against a soluble liver antigen. Lancet. 1987;1(8528):292294. doi: 10.1016/s0140-6736(87)92024-1.

15. Kanzler S, Weidemann C, Gerken G, Löhr HF, Galle PR, Meyer zum Büschenfelde KH, Lohse AW. Clinical significance of autoantibodies to soluble liver antigen in autoimmune hepatitis. J. Hepatol. 1999;31(4):635-640. doi: 10.1016/s0168-8278(99)80342-0.

16. Czaja AJ, Donaldson PT, Lohse AW. Antibodies to soluble liver antigen/liver pancreas and HLA risk factors for type 1 autoimmune hepatitis. Am. J. Gastroenterol. 2002;97(2):413419. doi: 10.1111/j.1572-0241.2002.05479.x.

17. Lohse AW, Mieli-Vergani G. Autoimmune hepatitis. J. Hepatol. 2011;55(1):171-182. doi: 10.1016/j. jhep.2010.12.012.

18. Autoimmunnyj gepatit. Rasprostranennost, prichiny, diagnostika i lechenie, prognoz [Internet]. Available from: http://kingmed.info/articles/Obshchaya_vrachebnaya _praktika/Gastroenterologiya/article_69/Autoimmunniy_gepatit (Russian).

19. Szabó Z. The role of liver biopsy in the diagnosis of autoimmune hepatitis. Orv. Hetil. 2006;147(35):1697-1702.

20. Aizawa $Y$, Abe H, Sugita $T$, Seki N, Chuganji $Y$, Furumoto Y, Sakata A. Centrilobular zonal necrosis as a hallmark of a distinctive subtype of autoimmune hepatitis. Eur. J. Gastroenterol. Hepatol. 2016;28(4):391-397. doi: 10.1097/ MEG.0000000000000545.

21. Zen Y, Notsumata K, Tanaka N, Nakanuma Y. Hepatic centrilobular zonal necrosis with positive antinuclear antibody: a unique subtype or early disease of autoimmune hepatitis? Hum. Pathol. 2007;38(11):1669-1675. doi: 10.1016/j.humpath.2007.03.019.

22. Hofer H, Oesterreicher C, Wrba F, Ferenci P, Penner E. Centrilobular necrosis in autoimmune hepatitis: a histological feature associated with acute clinical presentation. J. Clin. Pathol. 2006;59(3):246-249. doi: 10.1136/ jcp.2005.029348.

23. Duclos-Vallée J-C, Ichai $P$, Samuel $D$. Autoimmune acute liver failure. Hepatology. 2011;54(1):372-373. doi: 10.1002/ hep.24337. 
24. Stravitz RT, Lefkowitch JH, Fontana RJ, Gershwin ME, Leung PSC, Sterling RK, Manns MP, Norman GL, Lee WM; Acute Liver Failure Study Group. Autoimmune acute liver failure: proposed clinical and histological criteria Hepatology. 2011;53(2):517-526. doi: 10.1002/hep.24080.

25. Lotowska JM, Sobaniec-Lotowska ME, Daniluk U, Lebensztejn DM. Glassy droplet inclusions within the cytoplasm of Kupffer cells: A novel ultrastructural feature for the diagnosis of pediatric autoimmune hepatitis. Dig. Liver Dis. 2017;49(8):929-933. doi: 10.1016/j.dld.2017.04.001.

26. Tucker SM, Jonas MM, Perez-Atayde AR. Hyaline droplets in Kupffer cells: a novel diagnostic clue for autoimmune hepatitis. Am. J. Surg. Pathol. 2015;39(6):772-778. doi: 10.1097/PAS.0000000000000395.

27. Himoto $T$, Kadota $K$, Fujita $K$, Nomura $T$, Morishita $A$, Yoneyama $\mathrm{H}$, Masaki $\mathrm{T}$. The pathological appearance of hyaline droplets in Kupffer cells is not specific to patients with autoimmune hepatitis. Int. J. Clin. Exp. Pathol. 2017;10(8):8703-8708.

28. Łotowska JM, Sobaniec-Łotowska ME, Sobaniec $P$ Lebensztejn DM. Liver sinusoidal endothelial cells in morphogenesis of pediatric autoimmune hepatitis. Ultrastructural characteristics - a novel report. Pol. J. Pathol 2018:69(4):327-334 doi 10.5114/pjp.2018.81691.

29. Bach N, Thung SN, Schaffner F. The histological features of chronic hepatitis $\mathrm{C}$ and autoimmune chronic hepatitis: a comparative analysis. Hepatology. 1992;15(4):572-577. doi: 10.1002/hep.1840150403.

30. Autoimmunnyj gepatit: obzor gistologicheskih osobennostej, vkljuchennyh $v$ uproshhennye kriterii, predlozhennye Mezhdunarodnoj gruppoj autoimmunnogo gepatita, predlozhenie Novyh gistologicheskih kriteriev [Internet] Available from: https://rus.kyhistotechs.com/autoimmunehepatitis-review-histologic-features-included-simplifiedcriteria-proposed-international-autoimmune-75677567 (Russian)

31. Portnov A. Autoimmunnyj gepatit: prichiny i patogenez [Internet]. Available from: https://ilive.com.ua/health/auto-

Конфликт интересов. Авторы заявляют об отсутствии конфрликта интересов.

Финансирование. Исследование проведено без спонсорской поддержки.

Соответствие принципам этики. Исследование одобрено локальным этическим комитетом.

\section{Сведения об авторах:}

Цыркунов Владимир Максимович, д-р мед. наук, професcop; Гродненский государственный медицинский университет; e-mail: tvm111@mail.ru, ORCID: 0000-0002-9366-6789

Прокопчик Николай Иванович, канд. мед. наук, доцент; Гродненский государственный медицинский университет e-mail: prokopni@mail.ru, ORCID: 0000-0001-9319-9896

Андреев Виктор Павлович, канд. биол. наук, професссор Гродненский государственный медицинский университет; e-mail: andrvp@yandex.ru immunnyy-gepatit-prichiny-i-patogenez_85540i15947.html (Russian).

32. Hennes EM, Zeniya M, Czaja AJ, Parés A, Dalekos GN, Krawitt EL, Bittencourt PL, Porta G, Boberg KM, Hofer $\mathrm{H}$, Bianchi FB, Shibata M, Schramm C, Eisenmann de Torres B, Galle PR, McFarlane I, Dienes HP, Lohse AW; International Autoimmune Hepatitis Group. Simplified criteria for the diagnosis of autoimmune hepatitis. Hepatology. 2008;48(1):169-176. doi: 10.1002/hep.22322.

33. Desmet VJ, Gerber M, Hoofnagle JH, Manns M, Scheuer PJ. Classification of chronic hepatitis: diagnosis, grading and staging. Hepatology. 1994;19(6):1513-1520.

34. Kessler WR, Cummings OW, Eckert G, Chalasani N Lumeng L, Kwo PY. Fulminant hepatic failure as the initial presentation of acute autoimmune hepatitis. Clin. Gastroenterol. Hepatol. 2004;2(7):625-631. doi: 10.1016/ s1542-3565(04)00246-0.

35. Burgart LJ, Batts KP, Ludwig J, Nikias GA, Czaja AJ. Recent-onset autoimmune hepatitis. Biopsy findings and clinical correlations. Am. J. Surg. Pathol. 1995;19(6):699708. doi: 10.1097/00000478-199506000-00010.

36. Manns MP, Czaja AJ, Gorham JD, Krawitt EL, Mieli-Vergani G, Vergani D, Vierling JM; American Association for the Study of Liver Diseases. Diagnosis and management of autoimmune hepatitis. Hepatology. 2010;51(6):2193-2213. doi: $10.1002 /$ hep.23584.

37. Gleeson D, Heneghan MA; British Society of Gastroenterology. British Society of Gastroenterology (BSG) guidelines for management of autoimmune hepatitis. Gut. 2011;60(12):1611-1629. doi: 10.1136/gut.2010.235259.

38. Gutkowski K, Hartleb M, Kacperek-Hartleb T, Kajor M, Mazur W, Zych W, Walewska-Zielecka B, Habior A Sobolewski M. Laboratory-based scoring system for prediction of hepatic inflammatory activity in patients with autoimmune hepatitis. Liver Int. 2013;33(9):1370-1377. doi: 10.1111/liv. 12198

Conflict of interest. The authors declare no conflict of interest.

Financing. The study was performed without external funding.

Conformity with the principles of ethics. The study was approved by the local ethics committee.

Information about authors:

Tsyrkunov Vladimir, PhD, MD (Medicine), Professor; Grodno State Medical University; e-mail: tvm111@mail.ru, ORCID: 0000-0002-9366-6789

Prokopchik Nikolaj, PhD (Medicine), Associate Professor; Grodno State Medical University; e-mail: prokopni@mail.ru, ORCID: 0000-0001-9319-9896

Andreev Viktor, PhD (Biology), Professor; Grodno State Medical University; e-mail: andrvp@yandex.ru
Поступила: 05.05.2021

Принята к печати: 07.05.2021
Received: 05.05.2021

Accepted: 07.05.2021 